\title{
Diagnostics of the bainite transformation mechanism and the effect of normalizing and tempering on the hardness and microstructure of the new Cr-Mo-V-Ti steel for operation at elevated temperature
}

\author{
Zdzisław Ławrynowicz ${ }^{1, *}$ \\ ${ }^{1}$ University of Science and Technology UTP, Mechanical Engineering Faculty, Department of \\ Materials Science and Engineering, Av. Kaliskiego 7, 85-796 Bydgoszcz, Poland
}

\begin{abstract}
The Cr-Mo-V-Ti based low alloy steels are widely used in thermal power plants because of their ability to withstand elevated temperatures and high pressure under continuous service. In the present work conventional heat treatment like normalizing and tempering of the alloys has been performed. The material used in this study was the laboratory prepared experimental low alloy Cr-Mo-V-Ti steel. Samples were austenitized at $980^{\circ} \mathrm{C}$ for 0.5 hour air cooled and tempered at 500 , $550,600,650,700$ and $750^{\circ} \mathrm{C}$ for 1 hour. Mechanism of bainite transformation has been studied in Fe-C-Cr-Mo-V-Ti steel using high speed dilatometry. These experimental data indicate that bainitic ferrite forms by a displacive transformation mechanism, but soon afterwards, excess of carbon is partitioned into the residual austenite. The changes observed in the microstructure of the steel tempered at the higher temperature, i.e. $750^{\circ} \mathrm{C}$ were more advanced than those observed at the temperature of $500^{\circ} \mathrm{C}$. Performed microstructural investigations have shown that the degradation of the microstructure of the examined steel was mostly connected with the processes of recovery and polygonization of the matrix, disappearance of lath bainitic microstructure and the growth of the carbides. The magnitude of these changes depended on the temperature of tempering.
\end{abstract}

\section{Introduction}

The first Cr-Mo steels were used for conventional power-generation applications in the 1920s. The $2 \frac{1}{4} \mathrm{Cr}-1 \mathrm{Mo}$ (nominally Fe-2.25Cr-1.0 Mo-0.3Si-0.45Mn-0.12C) steel, designated by ASTM as Grade 22, was introduced in the 1940s and is still widely used today. The next generation of heat-resistant steels, in addition to increased chromium, involved primarily the addition of the carbide formers vanadium and niobium to chemical compositions (i.e. T22 steel) to add precipitate strengthening and in some cases, a small molybdenum addition was made for further solid-solution strengthening [1,2,3]. Typically Cr-Mo steels are intended for boiler tubes, wire pairs, parts of boilers and steam turbines, components and other equipment operating at temperatures up to $580^{\circ} \mathrm{C}$ [4].

The efficiency of power plants could be improved by enhancing the steam parameter. At present, heat-resistant steels for the high-steam parameter of $650^{\circ} \mathrm{C}$ are being developed. This has put heat-resistant steels such as T/P91, T/P92 and E211 out of consideration because of the loss of the microstructure stability during service at the high temperature [5-7]. More advanced steels should be developed to meet this requirement. It is well accepted in heat-resistant steels that highly stable microstructure will produce excellent creep strength. The precipitates are basically $\mathrm{M}_{23} \mathrm{C}_{6}$ and $\mathrm{MX}$, and the MX-type carbides show much better stability than the $\mathrm{M}_{23} \mathrm{C}_{6}$ type carbide. In order to achieve microstructure

*Corresponding author: lawry@utp.edu.pl 
with high stability, stable precipitates such as MX-type carbides are expected in heat resistant steels [8-11].

The aim of the present investigations was to study the mechanism of bainite transformation and the influence of tempering temperature on microstructure previously normalized steel, the new experimental $\mathrm{Cr}-\mathrm{Mo}-\mathrm{V}$-Ti heat-resistant steel which contains more alloying contents relative to T22 $\left(2 \frac{1 / 4}{4} \mathrm{Cr}-1 \mathrm{Mo}\right)$ and other high-quality heat-resistant steels.

\section{Material and experimental procedures}

The chemical composition of the experimental Cr-Mo-V-Ti steel (denoted as 15HM2VT) is listed in Table 1 and the critical $A_{1}, A_{3}, B_{S}$ and $M_{S}$ temperatures are shown in Table 2.

Table 1. Chemical compositions of the 15HM2VT steel used in this study. All concentrations are given in wt.\% .

\begin{tabular}{|l|c|c|c|c|c|c|c|c|c|c|}
\hline Alloy & $\mathrm{C}$ & $\mathrm{Si}$ & $\mathrm{Cr}$ & $\mathrm{Mn}$ & $\mathrm{Mo}$ & $\mathrm{V}$ & $\mathrm{Ti}$ & $\mathrm{P}$ & $\mathrm{S}$ & $\mathrm{Al}$ \\
\hline 15HM2VT & 0.15 & 0.24 & 0.84 & 0.92 & 2.6 & 0.24 & 0.12 & 0.022 & 0.019 & 0.06 \\
\hline
\end{tabular}

Table 2. $A_{1}, A_{3}, B_{S}$ and $M_{S}$ temperatures.

\begin{tabular}{|l|c|c|c|c|c|c|c|c|c|c|}
\hline Alloy & \multicolumn{4}{|c|}{ Temperature, ${ }^{\circ} \mathrm{C}$} & \multicolumn{3}{|c|}{$\begin{array}{c}\text { Experimentally } \\
\text { determined *** }\end{array}$} & \multicolumn{4}{|c|}{$\begin{array}{c}\text { Thermodynamically } \\
\text { calculated }\end{array}$} \\
\hline & $A_{c_{1}}$ & $A_{c_{3}}$ & $A_{r_{I}}$ & $A_{r_{3}}$ & $M_{S}$ & $B_{S}$ & $M_{S}{ }^{*}$ & $B_{S}{ }^{*}$ & $M_{S}{ }^{* *}$ & $B_{S} * *$ \\
\hline 15HM2VT & 807 & 969 & 730 & 896 & 453 & - & 423 & 555 & 479 & 601 \\
\hline
\end{tabular}

* Assuming full austenitization $\left(1200^{\circ} \mathrm{C}\right)$ ensuring complete dissolving of carbides in austenite

** Assuming partial dissolving of carbides in austenite $\left(1000^{\circ} \mathrm{C}\right)$

*** After austenitization at $1000^{\circ} \mathrm{C} / 10 \mathrm{~min}$.

In order to establish the $A_{l}$ and $A_{3}$ temperatures (Table 2) dilatometric analysis was carried out on a Leitz-Wetzlar vacuum dilatometer using a $20 \mathrm{~mm}$ long by $3.5 \mathrm{~mm}$ diameter specimens. Adamel Lhomargy LK-02 high-speed dilatometer was used to establish change of length $(\Delta L / L)$ during bainitic transformation and the $M_{S}$ temperatures (Table 2). In order to ensure rapid quenching $\left(300 \mathrm{Ks}^{-1}\right)$ the specimens were $12 \mathrm{~mm}$ in length and $1.0 \mathrm{~mm}$ in diameter.

Optical microscopy was used to examine etched structures. Microscopic images were recorded using the inverted metallographic microscope Nikon MA100 equipped with the ERC5s digital camera and the ZEN 2011 archiving program. Specimens were etched in 2\% nital solution. The specimens for transmission electron microscopy (TEM) were machined to $3 \mathrm{~mm}$ diameter rods and subsequently were sliced into $0.35 \mathrm{~mm}$ thick discs while being kerosene cooled. The discs were subsequently ground down to a thickness of 40-50 $\mu \mathrm{m}$. These specimens were finally electropolished in a twin-jet at room temperature and at 55$60 \mathrm{~V}$ using a 25-pct glycerol, 5 pct perchloric acid and 70 pct ethanol mixture.

The retained austenite content was calculated from the $X$-ray intensities. A peak separation technique was used to separate the $(111)_{\gamma}$-reflection from the overlapping $(110)_{\alpha}$ reflection. Retained austenite was determined by method of direct comparison (AverbachCohen method).

Vickers HV30 hardness measurements were performed according to European Standard EN ISO 6507-1 on the Duramin Z-500 hardness tester. 


\section{Carbon concentration in austenite}

The dilatometry results showed that the relative length change during the formation of bainite increases as the isothermal transformation temperature decreases below the $B s$ temperature, then the amount of bainite formed is dependent on the transformation temperature.

The details for calculation of volume fraction of transformation and determined carbon concentration of the residual austenite are given in Table 3 . The carbon concentration in austenite, $x_{\gamma}$, was determined as detailed elsewhere [12] by dilatometry. All details of the determination of carbon content in residual austenite are described elsewhere $[12,13]$. The obtained results in the area of these issues were discussed in a separate publications $[13,14]$.

Table 3. Parameters for determination of volume fractions of transformation $\left(V_{\alpha}\right)$ and the carbon concentration of the residual austenite $x_{\gamma}$ after cessation of bainite reaction in 15HM2VT steel.

\begin{tabular}{|c|c|c|c|c|c|}
\hline $\begin{array}{c}\text { Transformation } \\
\text { temperature, }{ }^{\circ} \mathrm{C}\end{array}$ & $\begin{array}{c}a_{\gamma} \\
\mathrm{nm}\end{array}$ & $\begin{array}{c}a_{\alpha} \\
\mathrm{nm}\end{array}$ & $\begin{array}{c}\Delta L / L \\
\times 10^{-3}\end{array}$ & $V_{\alpha} * *$ & $\begin{array}{c}x_{\gamma} \\
\mathrm{mol}\end{array}$ \\
\hline 460 & 0.36278 & 0.28926 & 3.34 & 0.74 & 0.0224 \\
\hline 475 & 0.36290 & 0.28933 & 3.03 & 0.68 & 0.0185 \\
\hline 490 & 0.36302 & 0.28939 & 1.83 & 0.42 & 0.0110 \\
\hline 508 & 0.36317 & 0.28947 & 1.50 & 0.35 & 0.0100 \\
\hline 518 & 0.36325 & 0.28952 & 0.92 & 0.22 & 0.0085 \\
\hline
\end{tabular}

* Values of the dimentional changes accompanying the complete transformation of austenite to bainitic ferrite at the transformation temperature

** $V_{\alpha}$ measured data at the transformation temperature

\section{Phase diagram}

The determined carbon concentrations of the residual austenite at the different temperatures of bainite transformations are compared with the $T_{0}, T_{0}{ }^{\prime}, A^{\prime}{ }_{3}$ and $A^{\prime \prime}{ }_{3}$, phase boundaries for investigated steel. It is usually assumed that the point where the bainitic microstructure ceases to change represents full transformation. But in case of bainitic transformation, reaction ceases before the parent phase (austenite) has completely transformed. It means that at any temperature below $B_{S}$ and in the absence of any interfering secondary reactions only a limited quantity of bainitic ferrite forms before the reaction terminates $[15,16]$. The calculated details for phase diagrams of the 15HM2VT steel and the carbon concentrations in austenite, $x_{\gamma}$ at selected temperatures are shown in Table 4.

Table 4. Calculated details for phase diagram of the 15HM2VT steel and the carbon concentration in austenite, $x_{\gamma}$ at selected temperatures.

\begin{tabular}{|c|c|c|c|c|c|c|c|c|}
\hline \multirow{2}{*}{$\begin{array}{c}\text { Phase } \\
\text { boundaries }\end{array}$} & \multicolumn{8}{|c|}{ Transformation temperature, ${ }^{\circ} \mathrm{C}$} \\
\cline { 2 - 9 } & 700 & 600 & 518 & 508 & 490 & 475 & 460 & 400 \\
\hline & \multicolumn{7}{|c|}{ Carbon concentration on phase boundaries, mol } \\
\hline$A_{3}{ }^{\prime}$ & 0.0194 & 0.0471 & 0.0762 & 0.0795 & 0.0859 & 0.0917 & 0.0978 & 0.1212 \\
\hline$A_{3}{ }^{\prime}$ & 0.0143 & 0.0428 & 0.0727 & 0.0761 & 0.0828 & 0.0887 & 0.0949 & 0.1189 \\
\hline$T_{0}\left(x_{T_{0}}\right)$ & 0.0065 & 0.0139 & 0.0215 & 0.0223 & 0.0240 & 0.0254 & 0.0274 & 0.0354 \\
\hline$T_{0}{ }^{\prime}\left(x_{T_{0}}{ }^{\prime}\right)$ & & 0.0016 & 0.0106 & 0.0115 & 0.0135 & 0.0152 & 0.0172 & 0.0241 \\
\hline$x_{\gamma}$ & & & 0.0085 & 0.0100 & 0.0110 & 0.0185 & 0.0224 & \\
\hline
\end{tabular}

$A_{3^{\prime}}{ }^{\prime} x^{\gamma \alpha}$-paraequilibrium carbon concentration of austenite in mole fraction,

$A_{3}{ }^{\prime \prime}-x^{\gamma \alpha}+50 \mathrm{~J}$ - paraequilibrium carbon concentration of austenite in mole fraction but allowing for 
the $50 \mathrm{~J} / \mathrm{mol}$ stored energy,

$x_{T_{0}}-T$-zero carbon concentration in mole fraction,

$x_{T_{0}^{\prime}}$ - the same but allowing for the $400 \mathrm{~J} / \mathrm{mol}$ stored energy.

In presented diagram (Fig. 1) the reaction is found to stop when the average carbon concentration of the residual austenite is closer to the $T_{0}{ }^{\prime}$ curve than the $A^{\prime}{ }_{3}$ boundary. The diagram was calculated as in Ref. [12-13] using a model developed by Bhadeshia [14] based on the McLellan and Dunn quasi-chemical thermodynamic model [15]. The martensite and bainite reaction starts temperatures $M_{S}$ and $B_{S}$ were also marked on this diagrams. The paraequilibrium phase boundary is chosen because no substitutional alloying element partitioning occurs during bainite formation. The presented results can be explained when it is assumed that bainitic ferrite grows without diffusion, but any excess of carbon is soon afterwards rejected into the residual austenite by diffusion [16-17].

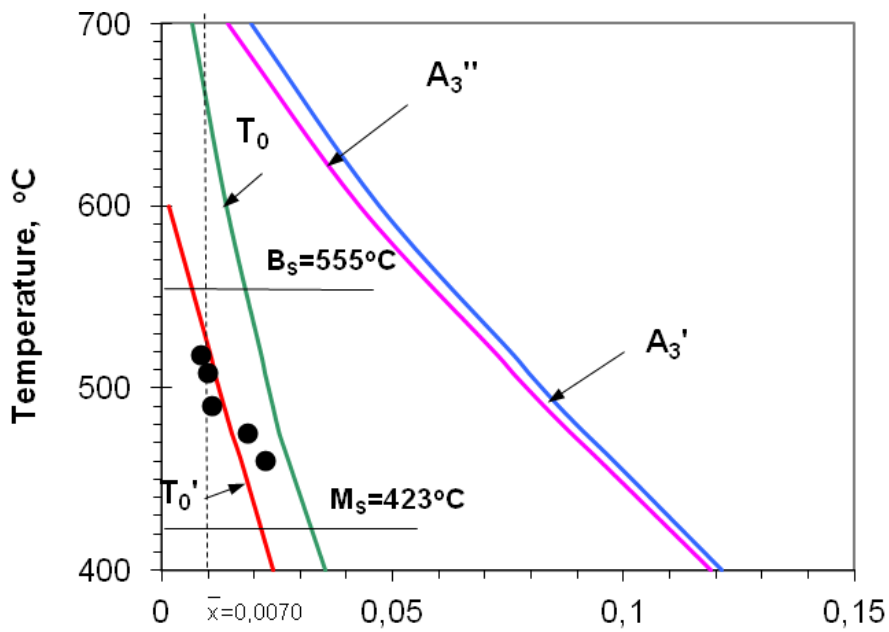

Carbon concentration in austenite, mole fraction

Fig. 1. The calculated phase boundaries $A 3^{\prime}, A_{3}{ }^{\prime \prime}, T_{0}$ and $T_{0}{ }^{\prime}$ for the investigated 15HM2VT steel together with all the experimental data of the measured carbon contents of the untransformed austenite (black circles).

If on the other hand, the ferrite grows with an equilibrium carbon concentration, then the transformation should cease when the austenite carbon concentration reaches the $A_{3}^{\prime}$ curve $[18,19]$. Thus, it is found experimentally that the transformation to bainite in studied steel does indeed stop close to the $T_{0}$ boundary (Fig. 1) and the analysis suggest that bainite grows by displacive mechanism of transformation, but carbon atoms partition into residual austenite shortly after growth is terminated. Similar results have previously obtained by Bhadeshia and Christian [19] and by Lawrynowicz and Barbacki for other alloys [13, 20].

\section{Retained austenite and hardness}

Volume fraction of retained austenite after normalizing followed by tempering at 500 and $550^{\circ} \mathrm{C}$ is presented in Fig. 2. The measured hardness change after normalizing and tempering of 15HM2VT steel is shown in Fig. 3 for different tempering temperatures. 




Fig. 2. Volume fraction of retained austenite after normalizing and tempering at 500 and $550^{\circ} \mathrm{C}$ of 15HM2VT steel.

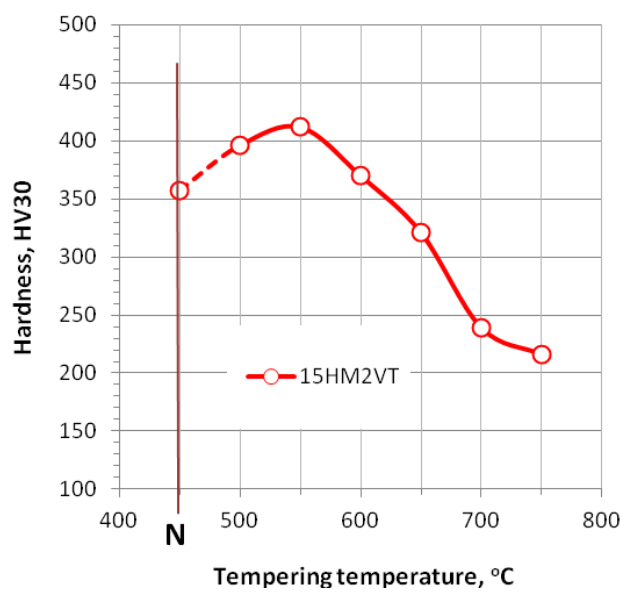

Fig. 3. Hardness change (HV30) after normalizing and tempering of 15HM2VT steel (N-means hardness after normalizing).

\section{Microstructural analysis}

Light optical microscopy and transmission electron microscopy micrographs of the investigated steel were taken on the normalized and tempered condition. The microstructure of the 15HM2VT steel is shown in Figures 4-7. It was found that for 15HM2VT steel the volume fraction of retained austenite decreased with increasing the tempering temperature (Fig. 2). The volume fraction of retained austenite after tempering above $600^{\circ} \mathrm{C}$ was beneath the level of resolution of applied X-ray diffractometer.

Microstructure of typical bainite after normalizing of the experimental15HM2VT steel is seen in Fig. 4. The morphology of the bainite is similar to low carbon lath martensite, where dislocated laths are separated by films and blocks of retained austenite. Careful examination of this microstructure shows no evidence of carbides precipitation. This structure, therefore, belongs to upper bainite assuming that upper bainite in this steel is a structure composed of carbide free bainitic laths with interlath retained austenite films $[16,19]$.

Figure 5 shows microstructure obtained by normalizing and tempering at $500^{\circ} \mathrm{C}$ for 1 hour. Transmission electron microscopy revealed that the sheaves were composed of small laths 
of ferrite and the microstructure contains only bainitic ferrite and carbon enriched residual austenite films. Bainitic ferrite laths of thickness about $0.2 \div 0.3 \mu \mathrm{m}$ form separately one from another. Retained austenite was present between the ferrite laths as thin discontinuous films. Carbides were difficult to observe in ferrite laths of thickness thinner than $0.3 \mu \mathrm{m}$. In this case films of residual austenite can accumulate all the excess carbon from supersaturated ferrite laths of thickness less than $0.3 \mu \mathrm{m}$. It is a possibility that, the carbon concentration of untransformed austenite is decreased by the carbide formation and then the reaction can proceed to a larger extent. The hardness of the steels is sensitive to changes in tempering temperature. With tempering at $550^{\circ} \mathrm{C}$, the hardness of the steel grows slightly compared to the hardness after normalization (Fig. 2). This shows that the way to strengthen the steels is mainly precipitate strengthening. The precipitation behavior of carbides is certain to affect the mechanical properties. The hardness of the steels shows normal response to the increasing tempering temperature above $550^{\circ} \mathrm{C}$, i.e. the hardness decreases with the increase of tempering temperature.

It is known that the formation of precipitates consumes dislocations. The carbide precipitation will decrease much the number of dislocations in the matrix, resulting in weakening of dislocation strengthening. On the other hand, the formation of carbides consumes the dissolved carbon, $\mathrm{Cr}$ and Mo which would provide a strong solid solution strengthening. Therefore, although the carbide precipitation could produce precipitation strengthening, it is not enough to compensate for the loss of dislocation strengthening and carbon, $\mathrm{Cr}$ and Mo solid solution strengthening.

When the tempering temperature is increased, a large amount of carbides form in the matrix. When the steel is heated at $600{ }^{\circ} \mathrm{C}$, a small amount of precipitates form on the lath of the bainitic ferrite and on the prior austenite grain boundaries and a certain amount of precipitates has formed in the matrix (Fig. 6 and Fig. 7).

The hardness rapidly decreases with increasing tempering temperature, especially when tempered above $600{ }^{\circ} \mathrm{C}$. When the steel is heated to 700 and $750{ }^{\circ} \mathrm{C}$, compared to the steel heated to 500 and $600{ }^{\circ} \mathrm{C}$, the number of precipitates in the microstructure within the bainitic ferrite laths and on grain boundaries increases significantly (Fig. 6 and Fig. 7). The carbide phase grows to a large size in a relatively short tempering time (1hour). The increasing amount of carbide phase could decrease the solid solution strengthening effect due to the consumption of dissolved $\mathrm{Cr}$, Mo, V and Ti atoms.

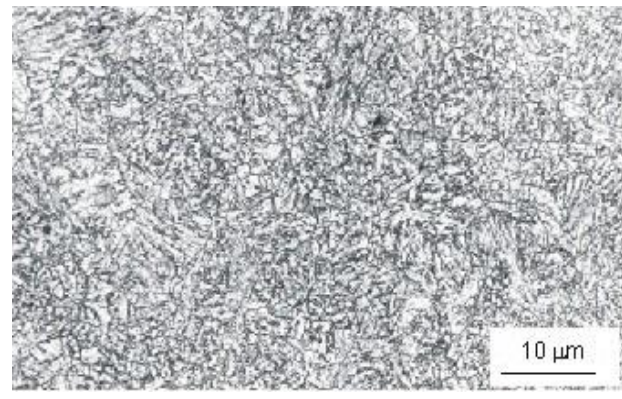

a)

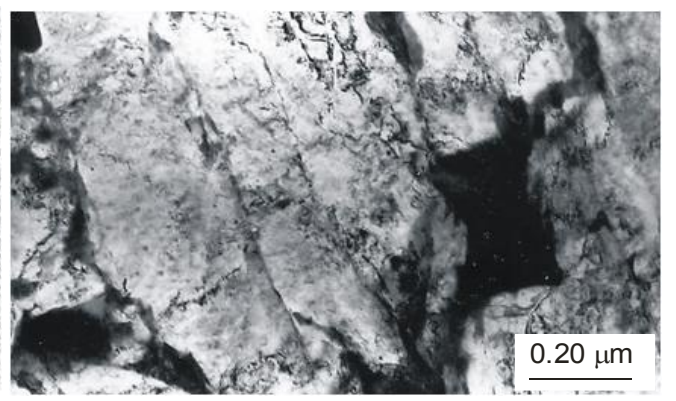

b)

Fig. 4. Microstructure of 15HM2VT steel after normalizing, a) light microscopy, etched with $2 \%$ nital, b) TEM, thin foil. 




a)

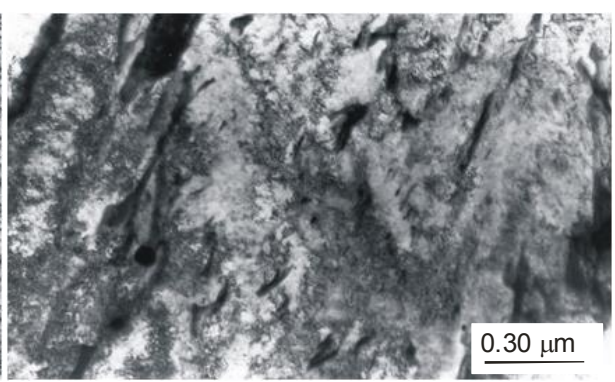

b)

Fig. 5. Microstructure of $15 \mathrm{HM} 2 \mathrm{VT}$ steel after normalizing and tempering at $500^{\circ} \mathrm{C}$ for $1 \mathrm{~h}$, a) light microscopy, etched with $2 \%$ nital, b) TEM, thin foil

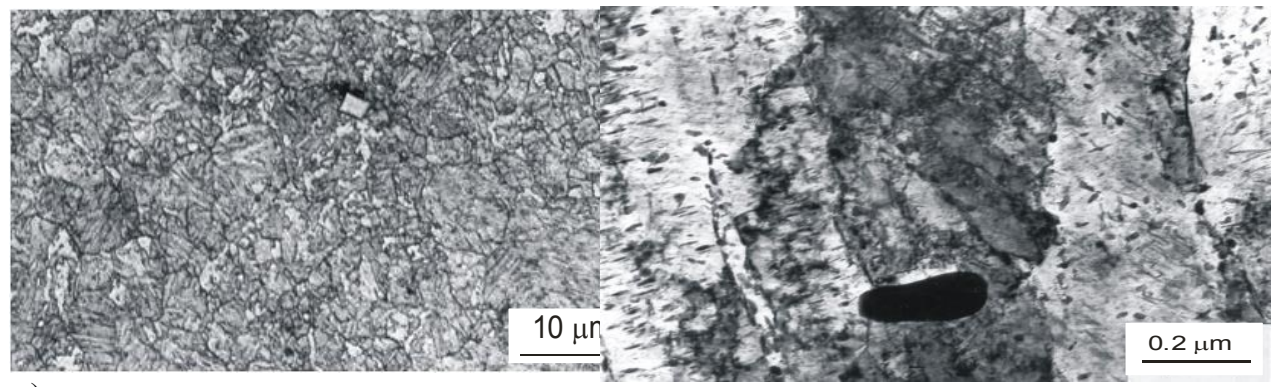

a)

b)

Fig. 6. Microstructure of $15 \mathrm{HM} 2 \mathrm{VT}$ steel after normalizing and tempering at $600^{\circ} \mathrm{C}$ for $1 \mathrm{~h}$, a) light microscopy, etched with $2 \%$ nital, b) TEM, thin foil.

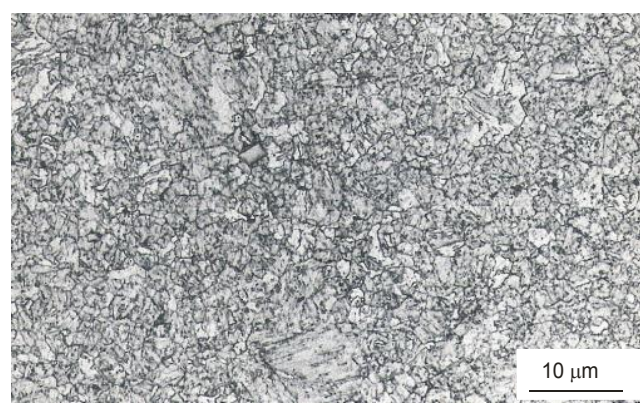

a)

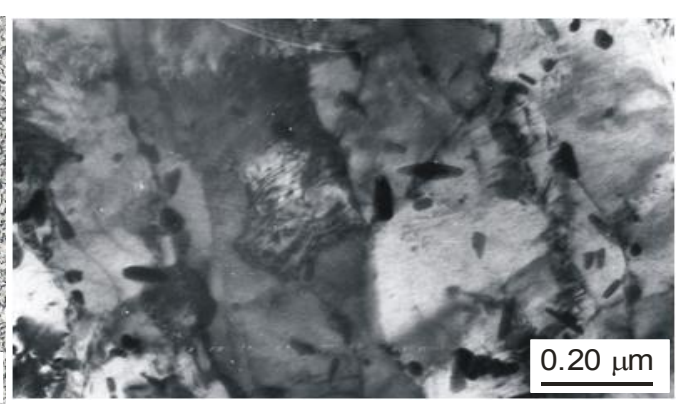

b)

Fig. 7. Microstructure of $15 \mathrm{HM} 2 \mathrm{VT}$ steel after normalizing and tempering at $700^{\circ} \mathrm{C}$ for $1 \mathrm{~h}$, a) light microscopy, etched with $2 \%$ nital, b) TEM, thin foil.

\section{Conclusions}

The austenite to bainite transformation and microstructure evolution have been studied in experimental low alloyed Cr-Mo-V-Ti steel using high speed dilatometry and transmission electron microscope backed by thermodynamic analysis. The main results obtained are summarized as follows:

1. The bainitic reaction stops prematurely as the carbon content of the residual austenite reaches the $T_{0}$ ' curve well before the paraequilibrium carbon concentration is achieved (given by the $A_{e 3}{ }^{\prime}$ curve). This indicates that the growth of bainitic ferrite is diffusionless.

2. After tempering at elevated temperatures $\left(500-550^{\circ} \mathrm{C}\right)$ previously normalized $\mathrm{Cr}-\mathrm{MoV}-\mathrm{Ti}$ steel hardness increases mainly by precipitate strengthening. Tempering at higher temperatures $\left(600-750^{\circ} \mathrm{C}\right)$ causes reduction in the dislocation density and polygonization of 
bainitic ferrite, previously normalized steel which is reflected in the hardness reduction. Along with the reduction in dislocation density, the $M_{23} C_{6}$ particles coarsen, allowing the bainitic ferrite laths to transform to more equiaxed subgrains. Along with the coarsening of the $M_{23} C_{6}$, there is also a coarsening in the $\mathrm{M}_{2} \mathrm{X}$ precipitate distribution, although these particles coarsen much more slowly than $M_{23} C_{6}$.

\section{References}

1. R. L. Klueh, OAK RIDGE NATIONAL LABORATORY, Oak Ridge, Tennessee, ORNL/TM, 176, 1-56 (2004)

2. B.S. Motagi, R. Bhosle, Int. J. of Eng. Res. Dev. 2, 07-13 (2012)

3. A. Zieliński, G. Golański, M. Sroka, Mater. Sci. \& Eng., A 682, 664-672 (2017)

4. H. Zheng-Fei, Thermal Power Plants, 1-266 (2012)

5. M. Dziuba-Kałuża, A. Zieliński, J. Dobrzański, M. Sroka, Arch. of Mater. Sci. and Eng. 66, 21-30 (2014)

6. M. Sroka, A. Zieliński, J. Mikuła J., Arch. Metall. Mater., 61, 1315-1320 (2016)

7. A. Zieliński, M. Miczka, B. Boryczko, M. Sroka, Arch. of Civ. and Mech. Eng. 16, 813-824 (2016)

8. J. Shen, H. Yang, Y. Li, S. Kano, Y. Matsukawa, Y. Satoh, H. Abe, J. of Alloys and Comp. 695, 1946-1955 (2017)

9. R. Kumari, G. Das, J. of Mater. \& Metall. Eng. 5, 7-14 (2015)

10. T. Shrestha, S. F. Alsagabi, I. Charit, G. P. Potirniche and M. V. Glazoff, Metals 5, 131-149 (2015)

11. T. R. Jacobs, Elevated temperature mechanical properties of line pipe steels, A thesis submitted to the Faculty and the Board of Trustees of the Colorado School of Mines, (2015)

12. Z. Ławrynowicz, Inter. Jour. of Eng. 12, 81-86 (1999)

13. Z. Ławrynowicz, A. Barbacki, Adv. in Mater. Sci. 2, 5-32 (2002)

14. H.K.D.H. Bhadeshia, Bainite in steels $2^{\text {nd }}$ ed., London, The Inst. of Mat., (2001)

15. R.B. McLellan, W.W. Dunn, J.Phys.Chem. Solids. 30, 2631-2637 (1969)

16. Z. Ławrynowicz, Adv. in Mat. Sci. 11, 13-19 (2011)

17. Z. Ławrynowicz, Mater. Sci. and Technol., 18, 1322-1324 (2002)

18. F.G. Caballero, M.K. Miller, S.S. Babu, C. Garcia-Mateo, Acta Materialia 55, 381-390 (2007)

19. H.K.D.H. Bhadeshia, J.W. Christian, 21A, Metall Trans. A, 767-797 (1990)

20. Z. Ławrynowicz, Mater. Sci. and Technol., 20, 1447-1454 (2004) 